\title{
New table grapes in turkey
}

\author{
A. Atak ${ }^{\mathrm{a}}$ and A.K. Kahraman \\ Atatürk Central Horticultural Research Institute, 77102 Yalova, Turkey
}

\begin{abstract}
Table grape consumption is increasing day by day all around the world. New varieties are derived from breeding programs in different countries around the world. Breeding programs in particular are shaped in accordance with the demands of consumers. Especially in recent years, the demands increased for cultivars of table grapes with large berry and maturation at different times, in Turkey as well as in the world market. Also, new cultivars which are tolerant to fungal diseases, late-season and can be stored for a long time had much demand in recent years. For this purpose, new table grapes with these characteristics have been developed by Yalova Atatürk from Central Horticultural Research Institute. Especially in the last few years, the numbers of new cultivars of a total of 12 varieties have been registered. Atak 77, Pembe 77, İsmetbey, Arifbey, Samanc1 çekirdeksizi, and Yalova Beyazitable grapes cultivars have been registered in the last few years among the new cultivars. Each one of them is different from the standard cultivars and has been registered with superior properties. Most of these cultivars need less pesticide application in high humidity areas and can be grown successfully. These new cultivars were tested in different ecology and determined suitable regions. These new table grape varieties started to be grown in different part of Turkey nowadays.
\end{abstract}

\section{Introduction}

The grape is the one of the most valuable horticultural crop in the world. The grape is one of the earliest domesticated fruit crops and, since antiquity; it has been widely cultivated and prized for its fruit and wine (Myles et al., 2010). The archaeological record suggests that cultivation of the domesticated grape, Vitis vinifera subsp. vinifera, began 6,000-8,000y ago in the Near East from its wild progenitor, Vitis vinifera subsp. sylvestris. Most grapes come from cultivars of Vitis vinifera L., the European grapevine native to the Mediterranean and Central Asia. Minor amounts of fruit and wine come from American and Asian. The fruit from the world's $\sim 8$ million ha of vineyard is mostly processed into wine, but some is destined for fresh consumption as table grapes, dried into raisins, processed into non-alcoholic juice, and distilled into spirits. The thousands of grape cultivars in use today have been generated since then by vegetative propagation and by crosses (McGovern, 2003).

Turkey also has very old viticulture history. Turkey has a history of viticulture dating back to 3500 B.D. Moreover, viticulture and wine production were established in eastern and south-eastern Anatolia (Çelik et al., 2000). Grape breeding programs are conducted in many countries; however, these programs vary in scope and size. Some breeding programs are focused on the production of rootstocks, wine, dessert grapes and raisins (Janick and Moore, 1996). In Turkey, breeding studies began in the 1970s and are currently in progress at various institutions. As a result, 12 new table grape cultivars have been registered and several cultivars from these studies have

\footnotetext{
${ }^{a}$ Corresponding author: e-mail: atakarif@gmail .com
}

been selected (Uslu and Samanc1, 1998; Özer et al., 2005; Atak et al., 2012). In addition, six new grape varieties, was registered in last two years. Table grapes takes place among the most consumed fruit. This situation increases the importance of quality characteristics of table grapes. For this reason, breeders of Turkey tried to increase the quality characteristics of table grape varieties. In addition, traits such as disease resistance and early-late harvest also were aimed in breeding programs. In this study, we examined the grape hybrids, hereinafter referred to as cultivars/candidates selected by Yalova Atatürk Central Horticultural Research Institute (YACHRI) morphology and some quality characteristics during the two different harvest season.

Arifbey: "Arifbey" is a Vitis vinifera grape variety derived from the crossing of the Beyaz Şam and Müşküle. "Arifbey" ripens second or third week of the August. It has a largely neutral flavour with slight fruity flavour in some observations. Some desirable traits of "Arifbey" are attractive light yellow berry colour. Berries average $7-8 \mathrm{~g}$, and cluster weight ranges from 150 to $250 \mathrm{~g}$, medium in size. Soluble solids content averages $14 \%$ and acidity also very low. So it is advisable for diabetics. Skin is edible. Fruit cracking was usually not found after summer rainfall during ripening or at maturity for "Arifbey". Vines usually have moderate vigour and yield and exhibit good cold hardiness in Northern part of Turkey. It has moderate resistance to common fungal diseases. This cultivar has excellent clusters that are fairly large and very loose to deter much bunch rot.

Samancı çekirdeksizi: "Samancı çekirdeksizi" is a Vitis vinifera grape variety derived from the crossing of 
Table 1. Cultivars were obtained breeding program by Atatürk Horticultural Central Research Institution (AHCRI).

\begin{tabular}{|c|c|c|c|}
\hline $\begin{array}{c}\text { Name of the } \\
\text { Cultivars }\end{array}$ & Parents & $\begin{array}{c}\text { Berry } \\
\text { Colour }\end{array}$ & Seeded / Seedless \\
\hline Uslu & Hönüsü $\times$ Siyah Gemre & Red & Seeded \\
\hline Yalova İncisi & Hönüsü $\times$ Siyah Gemre & Yellow & Seeded \\
\hline Yalova Misketi & Royal $\times$ Perle de Csaba & Black & Seeded \\
\hline İsmetbey & Siyah Gemre $\times$ Royal & Violet-Black & Seeded \\
\hline Pembe 77 & Alphonse Lavallée $\times$ Muscat Reine des Vignes & Red-Dark Red & Seeded \\
\hline Atak 77 & Beyaz Çavuş $\times$ Hamburg Muscat & Yellow & Seeded \\
\hline Arifbey & Beyaz Şam $\times$ Müşüle & Light Yellow & Seeded \\
\hline Samanc1 Çekirdeksizi & Beyaz Şam $\times$ Perlette & Yellow & Seedless \\
\hline Yalova Çekirdeksizi & Beyrut Hurmas1 $\times$ Perlette & Yellow & Seedless \\
\hline Ergin Çekirdeksizi & Beyrut Hurmas1 $\times$ Perlette & Yellow & Seedless \\
\hline Yalova Beyazı & Beyaz Çavuş $\times$ Cardinal & Yellow & Seeded \\
\hline Ata Sarıs1 & Beyaz Çavuş $\times$ Cardinal & Yellow & Seeded \\
\hline
\end{tabular}

Table 2. Cultivar candidate were obtained breeding program by Atatürk Horticultural Central Research Institution (AHCRI).

\begin{tabular}{|l|l|l|l|}
\hline $\begin{array}{l}\text { Name of the } \\
\text { Cultivars }\end{array}$ & Parents & $\begin{array}{l}\text { Berry } \\
\text { Colour }\end{array}$ & $\begin{array}{l}\text { Seeded } / \\
\text { Seedless }\end{array}$ \\
\hline $7 / 1$ & İskenderiye Misketi $\times$ Beyaz Şam & Yellow & Seeded \\
\hline $70 / 1$ & Hafizali $\times$ Cardinal & Yellow & Seeded \\
\hline $5 / 2$ & Siyah Gemre $\times$ Cardinal & Yellow & Seeded \\
\hline $85 / 1$ & Beyaz Çavuş $\times$ Perle de Csaba & Yellow & Seeded \\
\hline $86 / 1$ & Hafizali $\times$ Muscat Reine des Vignes & Yellow & Seeded \\
\hline $130 / 1$ & (Beyrut Hurmasi $\times$ Perlette) X Siyah Çekirdeksiz & Yellow & Seedless \\
\hline $53 / 1$ & Müşülle $\times$ Beyaz Şam & Yellow & Seeded \\
\hline
\end{tabular}

the Beyaz Şam and Perlette. "Samancıçekirdeksizi" is a yellow seedless grape with a crispy texture and high yields. It ripens end of the August. Berries average 4-5 g, and cluster weight ranges from 150 to $250 \mathrm{~g}$, medium in size. Soluble solids content over most of the cultivars and acidity also low. Vines usually have moderate vigour and high yield and exhibit good cold hardiness in Northern part of Turkey. It has moderate resistance to common fungal diseases. Gibberellic acid (GA) application makes larger the berries.

Yalova Beyazı: "Yalova Beyazı" is a Vitis vinifera grape variety derived from the crossing of the Beyaz Çavus and Cardinal. "Yalova Beyazı" ripens second or third week of the August. It has a largely neutral flavour with slight fruity flavour in some observations. This flavour become much greater towards maturity. Some desirable traits of this flavour become much greater towards maturity. "Yalova Beyazı" have large berries. Berries average $8 \mathrm{~g}$, and cluster weight ranges from 300 to $400 \mathrm{~g}$, medium to in size. Skin is edible. Fruit cracking and sensitivity to fungal diseases were found in humid regions during ripening or at maturity for "Yalova Beyazı". Vines usually have moderate vigour and yield and exhibit good cold hardiness in Northern part of Turkey.

İsmetbey: "İsmetbey" is a Vitis vinifera grape variety derived from the crossing of the Siyah Gemre and Royal. Registered in 2012 as new table grape cultivar. It ripens third or last week of the August. Vines usually have moderate yield (10-15 kg/vine). "İsmetbey" is a violet-black grape with a little crispy texture. Berries average $7-8 \mathrm{~g}$, and cluster weight ranges from 150 to $250 \mathrm{~g}$, medium in size. Vines usually have strong vigour. Berries have a slightly flattened end portion and it is extremely unique structure.

Atak 77: "Atak 77" is a Vitis vinifera grape variety derived from the crossing of the Beyaz Çavuş and Hamburg Muscat. Registered in 2012 as new table grape cultivar. It ripens very late in Yalova condition. Generally ripen end of the September and it can keep on the vine until December. Vines usually have strong vigour and high yield (15-20 kg/vine). "Atak 77" is a yellow grape with a large berries. Berries average $8 \mathrm{~g}$, and cluster weight ranges from 150 to $250 \mathrm{~g}$, medium in size. Vines usually have strong vigour. It has moderate to high resistance to common fungal diseases. Due to making a lot of bunches it is necessary to reduce the number of cluster with thinning. It is a late maturing variety so it is recommended for high altitude inner region.

Pembe 77: "Pembek 77" is a Vitis vinifera grape variety derived from the crossing of the Alphonse and Muscat Reine des Vignes. Registered in 2012 as new table grape cultivar. It ripens very late in Yalova condition. Generally ripen end of the September and it can keep on the vine until December. Vines usually have moderate vigour and yield ( $10 \mathrm{~kg} /$ vine). "Pembe 77 " is a red-dark red grape with a large berries. Berries average $8 \mathrm{~g}$, have special aroma, crispy structure and cluster weight ranges from 150 to $250 \mathrm{~g}$, medium in size. It has moderate to high resistance 
to common fungal diseases. It is a late maturing variety so it is recommended for high altitude inner region. For a good coloration, places where more day-night temperature difference must be selected.

Uslu: "Uslu" is a Vitis vinifera grape variety derived from the crossing of the Hönüsü and Siyah Gemre. Registered in 1990 as new table grape cultivar. It ripens Third week of the July (in Yalova condition) so it is very early cultivar. It ripens second week of the June in the south of Turkey. Vines usually have moderate vigour and yield ( $10 \mathrm{~kg} / \mathrm{vine})$. "Uslu" has red berry colour. Berries average 6-7 g, have neutral aroma, crispy structure and cluster weight ranges from 100 to $250 \mathrm{~g}$, small or medium in size. It has moderate resistance to common fungal diseases. It is a very early maturing variety so it is recommended for south region also for greenhouses. The major disadvantages are nonuniform berries, and cracking. "Uslu" is a blue, nonslipskin, seedless grape with exceptional fruity flavour. The skin is very thin, likely the thinnest of any Yalovadeveloped grape. Fruit cracking during rainy periods near or at harvest has rarely been seen. Negative aspects include uneven set of berries in some years resulting in reduced cluster fill.

Yalova İncisi: "Yalova İncisi" is a Vitis vinifera grape variety derived from the crossing of the Hönüsü and Siyah Gemre. Registered in 1990 as new table grape cultivar. It ripens last week of the July (in Yalova condition) so it is early cultivar. It ripens last week of the June in the south of Turkey. Vines usually have strong vigour and yield (15-20 kg/vine). "Yalova İncisi" has yellow berry colour. Berries average 6-7 g, have neutral aroma, and cluster weight ranges from 250 to $300 \mathrm{~g}$, medium in size. It has moderate resistance to common fungal diseases. It is an early maturing variety so it is recommended for south region also for greenhouses.

Yalova Çekirdeksizi: "Yalova çekirdeksizi" is a Vitis vinifera grape variety derived from the crossing of the Beyrut Hurmasıand Perlette. "Yalova çekirdeksizi" is a yellow seedless grape with high yields. It ripens second week of the August. Berries average 4-5 g, non-slipskin and cluster weight ranges from 250 to $300 \mathrm{~g}$, medium in size. Vines usually have moderate vigour and high yield and exhibit good cold hardiness in Northern part of Turkey. It has moderate resistance to common fungal diseases. Sometime berries would crack especially in the case of frequent irrigation.

Yalova Misketi: "Yalova Misketi" is a Vitis vinifera grape variety derived from the crossing of the Royal and Perle de Csaba. Registered in 1990 as new table grape cultivar. It ripens first week of the August (in Yalova condition) so it is early cultivar. Vines usually have strong vigour and yield ( $15 \mathrm{~kg} /$ vine). "Yalova Misketi" has black berry colour. Berries average $6 \mathrm{~g}$, have Muscat flavour, and cluster weight ranges from 200 to $250 \mathrm{~g}$, medium in size. It has moderate resistance to common fungal diseases. It is an early maturing variety so it is recommended for south region also for greenhouses.

Ata Sarısı: "Ata sarısı" is a Vitis vinifera grape variety derived from the crossing of the Beyaz Çavuş and Cardinal. "Ata Sarısı" ripens third week of the August. "Ata Sarısı" is non-slipskin, and very large berry. Berries average $10-12 \mathrm{~g}$, and cluster weight ranges from 350 to $500 \mathrm{~g}$, large to in size. One of the disadvantages is sensitivity to fungal diseases were found in humid regions during ripening or at maturity for "Ata Sarıs1". Vines usually have strong vigour and yield. In particular, huge berries, golden yellow colour and high yield increase table values. It is one the best price grape cultivar sale in the Turkish market.

Ergin Çekirdeksizi: "Ergin çekirdeksizi" is a Vitis vinifera grape variety derived from the crossing of the Beyrut Hurmasıand Perlette. "Ergin çekirdeksizi" is a yellow seedless grape with high yields (15-20 kg/vine). It ripens second week of the August. Cluster weight ranges from 500 to $600 \mathrm{~g}$, moderately thick skin. Vines usually have moderate vigour and high it has moderate resistance to common fungal diseases. Berries have moderate size (3-4 g). Gibberellic acid (GA) application makes larger the berries. However, 10-15 ppm GA application should be done in order to reduce number of clusters during the flowering.

\section{Material and methods}

Twelve new cultivars (Arifbey, İsmetbey, Pembe 77 and Atak 77) or candidates (7/1, 70/1, 5/2, 53/1, 130/1, 85/1, $86 / 1$ and 86/1) which obtained breeding program were analysed some morphologic and quality characteristics. Twelve cultivars/candidates were obtained at the Atatürk Horticultural Central Research Institution (AHCRI). The vines were approximately ten years old and were grown under identical conditions.

\section{Ampelographic evaluation}

Ampelographic characterisation of the cultivars/candidates was conducted using the Office International de la Vigne et du Vin (OIV) Descriptor List for Grape Varieties and Vitis species (OIV 2001). Highly discriminating characteristics were selected according to the recommendation of the OIV Descriptor List for Grape Varieties and Vitis species. Descriptors used in this study and their OIV codes are presented in Table 3.

Ampelographic observations were made during two consecutive vegetation periods. The characteristics of the vines were defined and measured according to OIV descriptors. The shoot tips were investigated when they were approximately $10-30 \mathrm{~cm}$ in height, and the first-four distal leaves of young leaves were evaluated. Mature leaf descriptions were obtained between berry set and beginning of berry maturity and were conducted on leaves above the cluster within the middle of the shoot. The clusters were measured at maturity, and berry characteristics were obtained from ripe berries located in 
Table 3. Morphologic characteristics of cultivars/candidates.

\begin{tabular}{|c|c|c|c|c|c|c|c|c|c|c|c|c|}
\hline \multirow[b]{2}{*}{ OIV CODE } & \multicolumn{12}{|c|}{ CULTIVARS OR CANDIDATES } \\
\hline & $\underset{\nabla}{ }$ & $\frac{d}{n}$ & $\$$ & 总 & 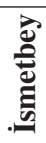 & 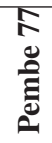 & $\begin{array}{l}\text { N } \\
\frac{1}{\pi} \\
\frac{\pi}{2}\end{array}$ & $\vec{\infty}$ & $\frac{1}{\sqrt{\infty}}$ & $\widehat{\infty}$ & $\vec{m}$ & స్త్ర \\
\hline 010 & 7 & 3 & 3 & 3 & 5 & 7 & 3 & 3 & 7 & 7 & 3 & 7 \\
\hline 017 & 7 & 5 & 5 & 5 & 7 & 7 & 7 & 7 & 5 & 7 & 7 & 7 \\
\hline 051 & 3 & 3 & 4 & 3 & 4 & 3 & 3 & 1 & 3 & 4 & 3 & 3 \\
\hline 053 & 3 & 3 & 5 & 1 & 7 & 1 & 7 & 9 & 3 & 5 & 3 & 5 \\
\hline 056 & 3 & 1 & 1 & 5 & 3 & 7 & 7 & 3 & 7 & 7 & 3 & 1 \\
\hline 065 & 5 & 5 & 5 & 5 & 5 & 5 & 7 & 7 & 5 & 5 & 5 & 5 \\
\hline 067 & 4 & 3 & 1 & 4 & 1 & 3 & 1 & 1 & 4 & 1 & 1 & 4 \\
\hline 068 & 3 & 2 & 3 & 3 & 3 & 3 & 2 & 3 & 3 & 3 & 3 & 2 \\
\hline 102 & 1 & 1 & 1 & 1 & 1 & 1 & 1 & 1 & 1 & 1 & 1 & 1 \\
\hline 103 & 1 & 2 & 4 & 4 & 4 & 4 & 3 & 2 & 4 & 3 & 2 & 2 \\
\hline 151 & 3 & 3 & 3 & 3 & 3 & 3 & 3 & 3 & 4 & 4 & 3 & 3 \\
\hline 204 & 5 & 5 & 7 & 3 & 5 & 5 & 5 & 7 & 3 & 3 & 5 & 7 \\
\hline 206 & 5 & 7 & 3 & 7 & 3 & 5 & 3 & 7 & 7 & 7 & 5 & 3 \\
\hline 220 & 3 & 7 & 7 & 7 & 7 & 7 & 7 & 7 & 5 & 5 & 3 & 3 \\
\hline 223 & 6 & 4 & 2 & 2 & 7 & 6 & 3 & 4 & 4 & 4 & 3 & 6 \\
\hline 225 & 1 & 1 & 1 & 1 & 6 & 5 & 1 & 3 & 1 & 1 & 1 & 1 \\
\hline 231 & 1 & 1 & 1 & 1 & 7 & 5 & 1 & 1 & 1 & 1 & 1 & 1 \\
\hline 232 & 2 & 2 & 2 & 2 & 3 & 1 & 2 & 2 & 2 & 2 & 3 & 2 \\
\hline 235 & 2 & 1 & 2 & 2 & 2 & 2 & 2 & 2 & 2 & 1 & 1 & 2 \\
\hline 236 & 2 & 2 & 1 & 1 & 1 & 5 & 1 & 1 & 2 & 2 & 1 & 1 \\
\hline 240 & 2 & 1 & 1 & 1 & 1 & 1 & 1 & 1 & 2 & 2 & 1 & 1 \\
\hline 241 & 3 & 3 & 3 & 3 & 3 & 3 & 3 & 3 & 3 & 3 & 2 & 2 \\
\hline 242 & 7 & 7 & 9 & 7 & 7 & 7 & 7 & 7 & 7 & 5 & 5 & - \\
\hline 243 & 5 & 9 & 9 & 7 & 9 & 9 & 7 & 5 & 9 & 7 & 1 & - \\
\hline 244 & 1 & 1 & 1 & 1 & 1 & 1 & 1 & 1 & 1 & 1 & 1 & 1 \\
\hline 301 & 3 & 7 & 5 & 3 & 7 & 5 & 9 & 5 & 3 & 5 & 5 & 5 \\
\hline 303 & 1 & 3 & 1 & 5 & 5 & 7 & 7 & 1 & 1 & 1 & 5 & 3 \\
\hline 202 & 7 & 7 & 5 & 9 & 9 & 7 & 7 & 7 & 3 & 3 & 9 & 7 \\
\hline 228 & 5 & 5 & 5 & 7 & 5 & 7 & 7 & 5 & 5 & 7 & 5 & 5 \\
\hline 238 & 3 & 5 & 5 & 7 & 5 & 7 & 5 & 7 & 3 & 7 & 7 & 3 \\
\hline 233 & 3 & 5 & 5 & 5 & 7 & 3 & 5 & 5 & 5 & 3 & 7 & 5 \\
\hline 304 & 3 & 3 & 3 & 5 & 5 & 7 & 7 & 3 & 1 & 1 & 5 & 5 \\
\hline 351 & 5 & 5 & 5 & 5 & 7 & 7 & 7 & 7 & 3 & 3 & 5 & 7 \\
\hline 501 & 7 & 7 & 7 & 9 & 7 & 7 & 7 & 7 & 5 & 5 & 7 & 9 \\
\hline 502 & 3 & 5 & 3 & 3 & 3 & 3 & 3 & 5 & 1 & 3 & 3 & 3 \\
\hline 503 & 5 & 9 & 7 & 7 & 7 & 9 & 7 & 7 & 5 & 5 & 3 & 3 \\
\hline 505 & 3 & 3 & 3 & 3 & 5 & 3 & 5 & 3 & 3 & 5 & 7 & 5 \\
\hline 506 & 3 & 3 & 3 & 3 & 3 & 3 & 3 & 1 & 3 & 3 & 3 & 3 \\
\hline 508 & 3 & 3 & 3 & 5 & 5 & 5 & 5 & 3 & 5 & 5 & 5 & 3 \\
\hline 458 & 7 & 7 & 7 & 7 & 7 & 7 & 7 & 7 & 7 & 7 & 7 & 7 \\
\hline 459 & 5 & 5 & 5 & 5 & 5 & 9 & 9 & 5 & 5 & 5 & 5 & 5 \\
\hline 452 & 5 & 7 & 7 & 7 & 7 & 7 & 7 & 7 & 7 & 7 & 7 & 7 \\
\hline 455 & 7 & 7 & 7 & 7 & 7 & 7 & 7 & 7 & 7 & 7 & 7 & 7 \\
\hline 456 & 5 & 7 & 5 & 5 & 5 & 7 & 7 & 5 & 5 & 5 & 5 & 5 \\
\hline
\end{tabular}

the middle of the bunch. On average, ten canes per variety were analysed after leaf fall.

\section{Degustation criteria}

Four different quality parameters were analysed during the two different season. General view of bunch (0-4), Berries shape, colour and size uniformity (0-5), Taste and aroma $(0-6)$, and skin-flesh and status of seeds (0-5) degustation criteria analysed for 12 different grape cultivars/candidates (Table 4).

\section{Skin colour of berry}

Surface colour measurements were determined using a CR-300 Chroma Meter (Minolta, Ramsey, NJ). The Chroma meter was calibrated on the CIE LAB colour space system using a white tile (Dc: $\mathrm{L}=97.79, \mathrm{a}=-0.11$, $\mathrm{b}=2.69)$. The "L" value represents lightness and "a" and 
Table 4. Two-year degustation scores of cultivars/candidates.

\begin{tabular}{|c|c|c|c|c|c|c|c|c|c|c|c|}
\hline \multirow{3}{*}{ 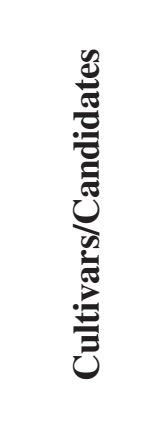 } & \multicolumn{8}{|c|}{ Degustation Criteria } & \multirow{3}{*}{ 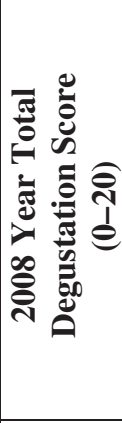 } & \multirow{3}{*}{ 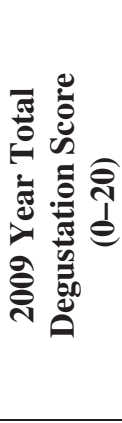 } & \multirow{3}{*}{ 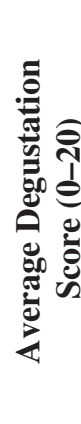 } \\
\hline & \multicolumn{2}{|c|}{$\begin{array}{c}\text { General view } \\
\text { of bunch } \\
(0-4)\end{array}$} & \multicolumn{2}{|c|}{$\begin{array}{c}\text { Berries } \\
\text { shape, colour } \\
\text { and size } \\
\text { uniformity } \\
(0-5)\end{array}$} & \multicolumn{2}{|c|}{$\begin{array}{c}\text { Taste and } \\
\text { aroma } \\
(0-6)\end{array}$} & \multicolumn{2}{|c|}{$\begin{array}{c}\text { Skin, flesh } \\
\text { and status of } \\
\text { seeds } \\
(0-5)\end{array}$} & & & \\
\hline & 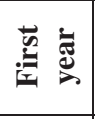 & 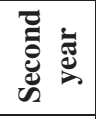 & $\stackrel{\omega}{\varpi}$ & 司 & 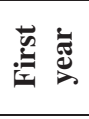 & 苞 & 矛恋 & 冚 & & & \\
\hline $7 / 1$ & 2 & 2 & 3 & 2 & 4 & 4 & 2 & 4 & 12 & 12 & 12 \\
\hline 70/1 & 3 & 4 & 4 & 5 & 4 & 4 & 3 & 5 & 14 & 17 & 16 \\
\hline $5 / 2$ & 4 & 3 & 4 & 4 & 5 & 5 & 4 & 4 & 17 & 16 & 17 \\
\hline $85 / 1$ & 2 & 2 & 3 & 2 & 5 & 5 & 4 & 4 & 13 & 13 & 13 \\
\hline $86 / 1$ & 2 & 2 & 3 & 3 & 5 & 4 & 4 & 3 & 14 & 13 & 14 \\
\hline $83 / 1$ & 3 & 4 & 3 & 4 & 4 & 5 & 5 & 3 & 14 & 16 & 15 \\
\hline Arifbey & 3 & 4 & 4 & 4 & 4 & 3 & 3 & 3 & 14 & 14 & 14 \\
\hline İsmetbey & 4 & 4 & 4 & 4 & 5 & 5 & 4 & 4 & 17 & 16 & 17 \\
\hline $130 / 1$ & 3 & 3 & 3 & 4 & 5 & 4 & 4 & 4 & 15 & 15 & 15 \\
\hline $53 / 1$ & 3 & 3 & 3 & 3 & 3 & 3 & 2 & 3 & 11 & 13 & 12 \\
\hline Atak 77 & 4 & 3 & 4 & 4 & 5 & 5 & 3 & 4 & 16 & 16 & 16 \\
\hline Pembe 77 & 4 & 3 & 5 & 3 & 5 & 5 & 4 & 4 & 18 & 15 & 17 \\
\hline
\end{tabular}

Table 5. Cultivars/candidates outside berry colour.

\begin{tabular}{|c|c|c|c|c|c|c|}
\hline \multirow{2}{*}{ Cultivar/ Candidate } & \multicolumn{5}{|c|}{ BERRY COLOUR (Lab)* } \\
\cline { 2 - 7 } & \multicolumn{3}{|c|}{ First year } & \multicolumn{3}{c|}{ Second year } \\
\cline { 2 - 7 } & $\mathbf{L}$ & $\mathbf{a}$ & $\mathbf{b}$ & $\mathbf{L}$ & $\mathbf{a}$ & $\mathbf{b}$ \\
\hline $\mathbf{7 / 1}$ & 39,63 & $-2,28$ & 15,52 & 40,45 & $-5,87$ & 16,57 \\
\hline $\mathbf{7 0 / 1}$ & 39,30 & $-2,78$ & 14,58 & 39,82 & $-5,20$ & 13,62 \\
\hline $\mathbf{5 / 2}$ & 39,08 & $-2,16$ & 12,83 & 40,63 & $-4,70$ & 13,40 \\
\hline $\mathbf{8 5 / 1}$ & 43,65 & $-3,70$ & 17,86 & 42,47 & $-5,40$ & 17,03 \\
\hline $\mathbf{8 6 / 1}$ & 43,34 & $-3,27$ & 12,66 & 41,97 & $-5,10$ & 14,40 \\
\hline $\mathbf{8 3 / 1}$ & 29,61 & 7,50 & 3,25 & 31,43 & 5,90 & 3,77 \\
\hline Arifbey & 44,24 & $-2,60$ & 16,00 & 41,87 & $-3,67$ & 13,09 \\
\hline Ismetbey & 25,30 & 2,41 & 1,24 & 24,62 & 3,08 & 0,35 \\
\hline $\mathbf{1 3 0 / 1}$ & 38,83 & $-1,42$ & 13,35 & 39,67 & 0,48 & 13,79 \\
\hline $\mathbf{5 3 / 1}$ & 42,52 & $-3,46$ & 19,37 & 41,62 & $-4,64$ & 18,45 \\
\hline Atak 77 & 39,16 & $-0,67$ & 9,83 & 40,43 & 1,10 & 9,08 \\
\hline Pembe 77 & 30,87 & 6,29 & 2,27 & 28,15 & 6,45 & 1,55 \\
\hline
\end{tabular}

* L: clarity or brightness, $+\mathrm{a}$ : direct red, $-\mathrm{a}$ : green, $+\mathrm{b}$ : direct yellow, $-\mathrm{b}$ : direct blue.

"b" values represent redness and yellowness, respectively. 30 berries were randomly chosen from each replication for recording the berry skin colour from three different part of each berry during the harvest (Table 5).

\section{Results and discussion}

Breeding projects were performed in the province of Yalova, particularly in humid climate. Especially cultivars/candidates, fungal diseases tolerant, were selected among the hybrids. After obtaining table grape with cross breeding, ampelographic characterization, degustation panel and determination of berry colour were analysed in order to understand quality level of candidates. Ampelographic characterisation of the cultivars/candidates was based ampelographic scoring (0-9) of OIV, 2001(Second Edition of the OIV Descriptor List for Grape Varieties and Vitis Species), is shown Table 3. Assessments can be summarized briefly as follows the results obtained;

Some ampelographic observations didn't show any difference for all cultivars/candidates. These are structure 
of surface (OIV 102), and degree of resistance to oidium (OIV 455). The maximum difference was obtained from berry shape (OIV 223), density of prostrate hairs between main veins on lower side of blade (OIV 053), length of seeds (OIV 242), and weight of seeds (OIV 243).

All of the new registered cultivars (Ismetbey, Atak 77 and Pembe 77) seeded and large berry. These varieties, and especially Pembe 77 and Atak 77 draw attention with late harvest, disease resistance, and also long storage life. These both cultivars are particularly suitable in humid and last-season table grape growing regions. After quality evaluations (Table 4) these varieties also received the highest scores. It means that they have high chance of consumer demand in the market. Also due to the different colours of new cultivars, it is advantage for different markets (Table 5).

Compared to the other cultivars/candidates $85 / 1$ and $86 / 1$ have very similar phenotypic characteristics. Both candidates have fully developed gynoecium fully developed gynoecium while others have fully developed stamens and reflexed stamens. However, because of the desire to pollinators in some years can make shot berries. For this reason, the time of flowering should be help for enough pollination. Despite this flower type, these varieties have Muscat flavour and ripen very early. It can be considered very early locations and greenhouse production.

Arifbey was distinguished particularly low total soluble solids and acidity. Especially it can be consumed by the growing number of diabetics. Shiny light yellow colour, large berries and high yield are the most important characteristics of Arifbey. Berries are not very dense on the bunch and it affects resistance of fungal diseases.

83/1, 53/1 and 130/1 were selected as cultivar candidates from F1 plot because they appeared fungal disease tolerant hybrids. $83 / 1$ has high yield potential and red berries but homogeneity of berry colour is n't enough level. 53/1 has also high yield potential but berry size is relatively small if compare other candidates. Among cultivars/candidates only 130/1 has seedless characteristic. Its berries are larger than most of the standard seedless cultivars. However, yields remained low in Yalova conditions. It will be decided to register will be given taking into account the results in other ecologies.

$70 / 1$ and 5/2 have large berries and yellow colour. 70/1 also has high yield potential but it is sensitive to fungal diseases especially powdery mildew. It can be grown in dry areas with a high quality berries but not in humid regions. 5/2 candidate have a full round berries and table corresponds to a very high value but yield is lower than the other candidates. Especially with high water soluble solids is suitable for lovers of sweet grapes.

The other candidate is $7 / 1$ and it is one of the earliest grapes. 7/1 can be harvested very early and berries have green-yellow colour. However, two most important problems of candidate are shot berry and sensitivity of fungal diseases. This situation is a problem especially in humid ecologies, where the drier climate was not a serious problem.

Degustation Test Score results were based on the average of two years. The highest score was obtained respectively by İsmetbey, Pembe 77, 5/2, Atak 77 and 70/1. The lowest score was obtained by 53/1 and 7/1 candidates. Small berry size of these candidates had been effective in this score. Also shot berries of 7/1 had been effective in this lowest score.

As a result of two years average analyses of skin berry colour values are as follows; Arifbey was the for the most brightness candidate relative to the average of two years, on the other hand İsmetbey was the most darkness cultivar. While $85 / 1$ had the highest green colour, 83/1 and Pembe 77 had the highest red colour. 53/1 had the highest yellow colour and İsmetbey had the highest blue colour. Especially red and black berry cultivars began to record more demand by producers and consumers in the last years. Also brightness plays an important role in consumer choice. Therefore İsmetbey, Atak 77, Pembe 77 and Arifbey had come to the fore with colours. Should be noted that especially in coloured varieties were can display some differences in colouration different ecologies. Similar results were obtained with these cultivars/candidates.

\section{Conclusions}

Registration of some candidates was started in the light of the obtained data of this study. Registration process of Ismetbey, Pembe 77 with dark skin colour and Atak 77 with light skin colour was completed in 2012. Also Arifbey, Samancı çekirdeksizi and Yalova beyazıjust registered in the beginning of the 2014. Registration had started some candidates which had especially with a high value of degustation score and relatively high yield potential. In addition, the potentials of these varieties were checked by adaptation studies of different ecologies. Now it is clear to grow new cultivars which part of the Turkey.

New table grapes were presented to our country and the world. New breeding program will be start soon by Ataturk Horticultural Central Research Institute. This time it will mainly focus fungal disease resistance cultivars.

This study was supported by, Ministry of Food Agriculture and Animal Husbandry, General Directorate of Agricultural Research and Policies.

\section{References}

[1] Atak A., Altındişli A, Gökçe A. F., Özer, C., 2012. Molecular and ampelographic characterization of some grape hybrids (Vitis vinifera L.). African Journal of Agricultural Research Vol. 7(33), 4596-4606

[2] Çelik H., Marasalı B., Söylemezoğlu G., Tangolar S., Gündüz M., 2000. Future prospect in Turkish viticulture. TMMOB The Chamber of Agricultural Engineers, Turkey Agricultural Engineers V. Technical Congress, Reports 2, Ankara, Turkey, pp. 645-678

[3] Janick J. and Moore N. J., 1996. Fruit Breeding. Volume II, Vine and Small Fruits, Newyork USA, pp. 300-347

[4] McGovern P. E., 2003. Ancient Wine: The Search for the Origins of Viniculture (Princeton Univ Press, Princeton) 
[5] Myles S., Boyko A. R., Brown P. J., Grassi F., Owens C. L., Aradhya M., Prins B., Reynolds A., Chia J. M., Ware D., Bustamante C. D., Buckler E. S., 2011. Genetic Structure and Domestication History of the Grape. PNAS 108:3530 [PubMed: 21245334]

[6] OIV (2001) Second Edition of the OIV Descriptor List for Grape Varieties and Vitis Species Website: http://www.oiv.int
[7] Özer C., Karauz A., Erdoğan N. K., Kirac1 M. A., Barış C., Gürnil K., 2005. Obtaining new seedless and early table grapes with hybridization. 6th National Viticulture Symposium, pp. 470-476

[8] Uslu İ. and Samanc1 H., 1998. Obtain new table grapes with crossing. 4th Viticulture Symposium 20-23 October 1998, Yalova, Turkey, pp. 17-23 